\title{
Prediction of reservoir parameters in gas hydrate sediments using artificial intelligence (AI): A case study in Krishna-Godavari basin (NGHP Exp-02)
}

\author{
Bappa MukherJeE ${ }^{1}$ and Kalachand SAin $^{1,2, *}$ \\ ${ }^{1}$ Seismic Group, CSIR-National Geophysical Research Institute, Uppal Road, Hyderabad 500007 , India. \\ ${ }^{2}$ Wadia Institute of Himalayan Geology, 33, General Mahadeo Singh Road, Dehradun 248 001, India. \\ *Corresponding author. e-mail: kalachandsain7@gmail.com
}

MS received 8 August 2018; revised 14 April 2019; accepted 23 April 2019; published online 15 July 2019

The estimation of accurate reservoir parameters is essential for conventional and non-conventional hydrocarbon prospects. An artificial neural network has been developed to predict the reservoir parameters (porosity and saturation of gas hydrates) in a silty-sand, sandy-silt and pelagic-poor clay reservoir at two neighbour wells using the petrophysical information at another well in the Krishna-Godavari basin. The well log data were acquired during the Expedition-02 of Indian National Gas Hydrates Program (NGHP Exp-02). The estimation of gas hydrate saturation using Archie's equation may be erroneous, as it is valid for the quantification of conventional hydrocarbons in the clean sand reservoir. Since the study area is clay dominated, it is subjective to adjust Archie's exponents so that it matches with the saturation, measured from the core data. To overcome this problem of estimating the reservoir parameters in such a scenario, first of all we have derived porosity from the density log data and estimated saturation by employing modified Archie's equation to the resistivity log data at one well. In order to train the network, the log data at one well are taken as inputs and corresponding porosity and saturation are taken as outputs. The reservoir parameters are then predicted at two neighbour wells using the wireline log data as input in those two wells. The predicted porosity and saturation of gas hydrates are alike to the traditionally estimated porosity and saturation at the neighbour wells. The predicted porosity in the studied region varies between 33 and $76 \%$, whereas the saturation of gas hydrates ranges between 3.39 and $86.92 \%$. This shows that the designed network can be used to estimate the reservoir parameters directly from the well log data in the same reservoirs.

Keywords. Gas hydrates; porosity; saturation; ANN; NGHP Exp-02.

\section{Introduction}

Assessment of gas hydrates in a marine environment is important as it is considered as a major unconventional energy resource of future. Gas hydrates have attracted the attention due to their natural occurrences along the outer continental margins and in the permafrost regions. Several countries have been pursuing research for the delineation and characterization of gas hydrates (Boswell et al. 2012; Ryu et al. 2013; Collett et al. 2014; Kumar et al. 2016a; Sain 2017) and understanding the production issues (Takahashi et al. 2005; Yamamoto et al. 2014; Kumar et al. 2016b). The production tests in the McKenzie delta (Canada), Alaska (USA), Japan continental margin and South China sea have spread the interest of gas hydrates as a feasible energy resource to the whole 
scientific community. Evaluating the petrophysical parameters such as the porosity, permeability and saturation of gas hydrates is very important in assessing a reservoir, monitoring the potentiality, field operations and geological interpretation (Wiener et al. 1991; Mohaghegh et al. 1996; Aminian and Ameri 2005). Porosity describes the volume fraction of the pore space and is related to the hydrocarbon reserves, which can be measured from wireline log data such as the neutron porosity, density porosity and sonic porosity (primary porosity, etc.), whereas the saturation $\left(S_{\mathrm{h}}\right)$ of gas hydrates can be estimated by measuring the chlorine concentration in the formation water (Ussler and Paull 2001; Malinverno et al. 2008). Otherwise, $S_{\mathrm{h}}$ can be directly obtained from the pressure cores, by measuring the gas volume produced during the dissociation of hydrate-bearing pressure cores (Dickens et al. 1997; Holland and Schultheiss 2014). Because of cost involvement, the coring and subsequent measurements are neither continuously performed throughout the wells, nor even acquired at every borehole site. Over a century, the well log data have been used for the estimation of reservoir parameters. The log data provide high resolution petro-physical information about the formation through which the borehole is drilled, and thus have been used to illustrate the in-situ properties of gas hydrates including the estimation of reservoir parameters (Guerin et al. 1999; Helgerud et al. 1999; Collett 2000, 2002; Hyndman et al. 2001; Lee and Collett 2005; Lee and Waite 2008). Rolon et al. (2005) generated synthetic log data from a suit of other known log data using artificial intelligence (AI) and tested at the neighbour wells. Helle et al. (2001) predicted the porosity and permeability from well log data using AI. Neural network analysis is one of the latest technologies available to the petroleum industry for analysing a large volume of data, even from a complex environment (Nikravesh and Aminzadeh 2003).

For the estimation of gas hydrates, an appropriate calibration of Archie's (1942) constants is a subjective task. Archie's empirical equation contains several constants, which have a wide range of values due to complexities of porous rocks. In fact, Archie's law was established for the estimation of fluid hydrocarbons in clean consolidated sand formation. In the Krishna-Godavari (KG) basin, the gas hydrates occur mostly in the fractures of the clay-dominated formations (Collett et al. 2008a). Therefore, it will not hold good for the estimation of solid gas hydrates unless some modifications are made to Archie's constants. Lee and Collett (2009) modified Archie's parameters $(a=3, m=2$ and $n=3)$ instead of ( $a=3.2, m=0.5$ and $n=2)$ to minimise the difference between the saturation, obtained from resistivity log by using Archie's equation and the core-derived saturation. Later on, Shankar and Riedel (2011) and Jana et al. (2017) estimated the gas hydrates by using modified Archie's constants. The effective medium theory has also been implemented for the estimation of gas hydrates (Ghosh et al. 2010; Shankar et al. 2013; Xiao et al. 2017) in the fracture shale. Further, AI techniques have been used to map the porosity of gas hydrate bearing sediments (Singha et al. 2014) as well as to estimate the saturation of gas hydrates (Singh et al. 2016). The porosity has been calculated from the seismic data in the $\mathrm{KG}$ basin (Chatterjee et al. 2016). The rock physics model of the wireline log data has also been reported in the KG basin (Singha and Chatterjee 2017).

The petrophysical parameters of the rocks are empirically or sometimes directly related to the reservoir parameters (Serra 1984; Schlumberger 1989). In complex geological setup, the ability to obtain reliable and accurate reservoir properties is crucial (Mohaghegh 2000), and most of the researchers have used the AI techniques (Fung et al. 1997; Wang et al. 2013; Singh et al. 2015; Salehi et al. 2017). This technique has the remarkable ability in establishing a complicated mapping between the nonlinearly linked input and output data (Nakutnyy et al. 2008). Additionally, this technique is tolerant to noise and has linear computation complexity and robustness to the reservoir characterisation system.

In this paper, we have performed the multi-layer feed-forward (MLF) neural network to predict the porosity as well as the saturation of gas hydrates at the neighbour wells from log data at other well. In order to conduct these predictions, we have analysed the wireline log data such as the resistivity $\log$ (RES), bulk density log (RHOB), P-wave velocity $\log \left(V_{\mathrm{P}}\right)$ and density porosity $\log \left(\phi_{\mathrm{D}}\right)$ from three holes (NGHP-02-17-C, NGHP-02-19-C and NGHP-02-22-C) in the KG basin. The caliper log data were used to comprehend the breakout and washout portion in the depth range of study in these wells. The wireline log data at one well (NGHP-02-17-C) were used to train the network. Afterwards, the log data from other two wells (NGHP-02-19-C, NGHP-02-22-C) were used to predict the associated porosity and saturation from the established network. Finally, the predicted 
results are validated by the reservoir properties, which are derived traditionally.

\section{MLF neural network}

Artificial neural networks (ANNs) were invented for an intelligent information processing system, based on the operating biological neural systems, firstly introduced by McCulloch and Pitts (1943). The backpropagation (BP) is a common method to train a network, which was originally introduced by Linnainmaa (1970). Later, the importance of BP was appreciated and a faster work flow was documented by Rumelhart et al. (1986). The aim of the supervised learning algorithm (BP) is to repeatedly adjust the weights by connecting the neurons of different layers in such a way that the neural network can map out an arbitrary nonlinear relationship between the inputs and outputs (Fausett 1993; Salehi et al. 2017). The simplest network consists of one input, one hidden and one output layer (Rogers et al. 1992; Benaouda et al. 1999). The number of input and output nodes is assigned to a number of input and output parameters, respectively (He 1992; Jiao 1992). Theoretically, it was proved that a single hidden layer network can also achieve the needed precision (Zhuang et al. 1992). Furthermore, a multi-hidden layer network can be used for a stepwise low-value weight adjustment and store them according to the weight distribution (Kexiong and Laibin 2008).

Here we have used the four-layer (one input, two hidden and one output) network for the validation and predicting outputs. The network-1, designed for the prediction of porosity, and the network-2, for the saturation of gas hydrates, are graphically represented in figure 1 ( $a$ and $b)$, respectively. An important step in the BP network is a selection of transfer function. So to deal with the nonlinear geo-scientific data, the Tan-sigmoid function (Moazzeni and Haffar 2015) has been used for nonlinear mapping, which is defined as

$$
f\left(x_{i}\right)=\operatorname{Tansig}\left(x_{i}\right)=\frac{\exp \left(x_{i}\right)-\exp \left(-x_{i}\right)}{\exp \left(x_{i}\right)+\exp \left(-x_{i}\right)} .
$$

This function is graphically represented in figure 1(c), and is considered as a transfer function for all the layers during training of the network. The feed-forward BP network is exploited with the TRAINGDA training function, LEARNGDM adaptation learning function and mean square error (MSE) performance function.

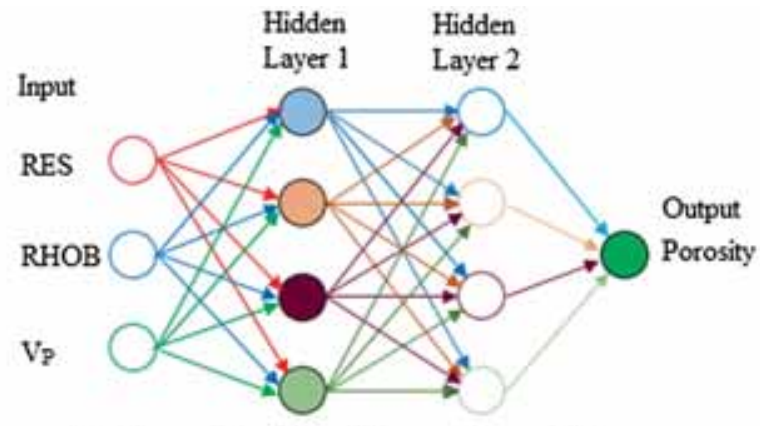

(a) Network-1 designed for porosity prediction.

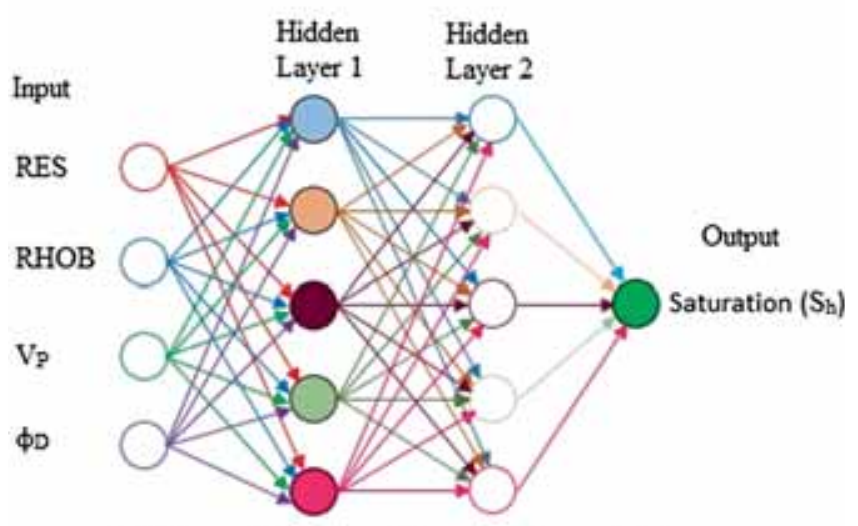

(b) Network-2 designed for saturation prediction.

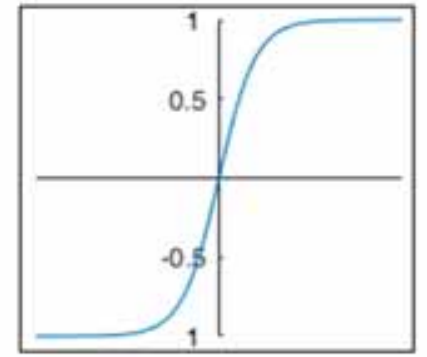

(c) Tan-Sigmoid transfer function.

Figure 1. (a) Network-1 designed for porosity prediction. (b) Network-2 designed for saturation prediction. (c) Tansigmoid transfer function.

The MSE is expressed as

$$
\mathrm{MSE}=\frac{1}{N} \sum_{k=1}^{N}\left(Y_{k}-T_{k}\right)^{2},
$$

where $N$ is the number of data points, $Y_{k}$ is denoted as the predicted output (obtained from the MLF network) and $T_{k}$ is denoted as the target, obtained from traditional analysis coupled with validation by core data.

\section{Case study}

The KG basin is a well-known proliferous basin for both conventional and un-conventional hydrocarbon resources, situated in the east coast of India. It 
covers almost $15,000 \mathrm{~km}^{2}$ area in onshore and around $25,000 \mathrm{~km}^{2}$ area in the offshore region. The stratigraphic age of the KG basin belongs to the Late Carboniferous to Pleistocene. Sediments are mainly composed of siliciclastic sediments, biogenic sediments, mixed sediments and firmness (composed of soft to hard clays and oozes). Wireline $\log$ data at NGHP-02-17-C, NGHP-02-19-C and NGHP-02-22-C sites are analysed here. The geographical location of the study area and the borehole locations are shown in figure 2 ( $a$ and $b$ ), respectively. The wireline log data (RES, RHOB,
$\left.V_{\mathrm{P}}, \phi_{\mathrm{D}}\right)$ from holes NGHP-02-17-C, NGHP-02-19-C and NGHP-02-22-C are shown in figures $3-5$, respectively. The bottom simulating reflector (BSR) is situated at around $313 \mathrm{~m}$ at hole NGHP-02-17-C, shown in figure 3 , whereas the BSRs are situated below the studied depth range for other holes (NGHP-02-19-C and NGHP-02-22-C).

Traditionally, the saturation of gas hydrates is estimated from resistivity log data using modified Archie's equation. An empirical relationship of the resistivity of a clean coarse-grained fully brinesaturated reservoir $\left(R_{\mathrm{o}}\right)$, the intrinsic formation

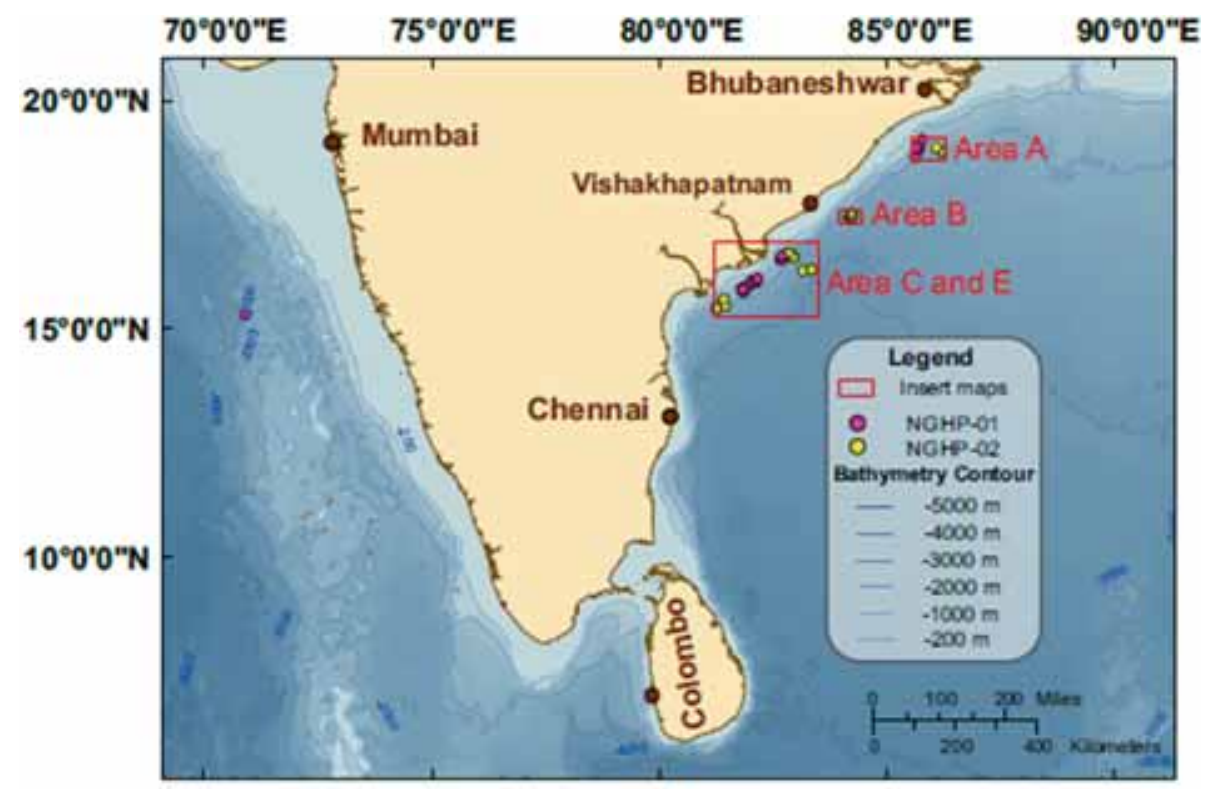

(a)

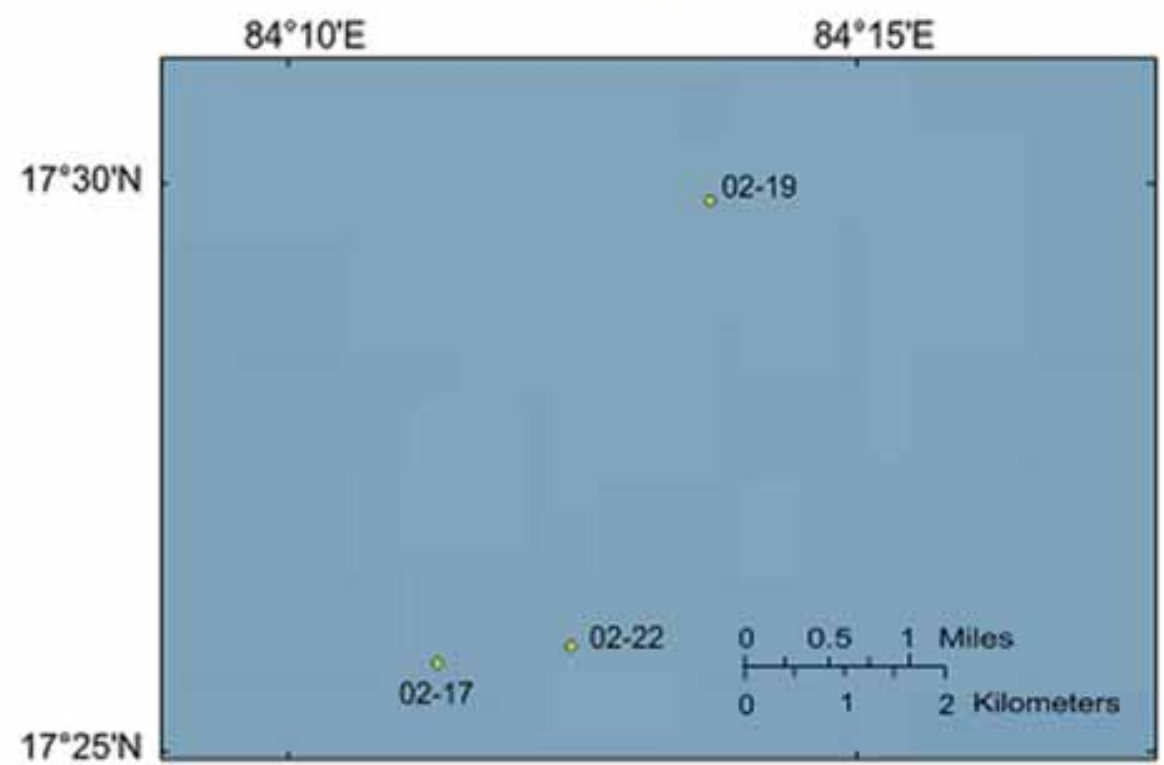

(b)

Figure 2. (a) Study area in the KG basin and the location of drill sites by NGHP expeditions. (b) Geographic location of the holes (NGHP-02-17-C, NGHP-02-19-C and NGHP-02-22-C). 


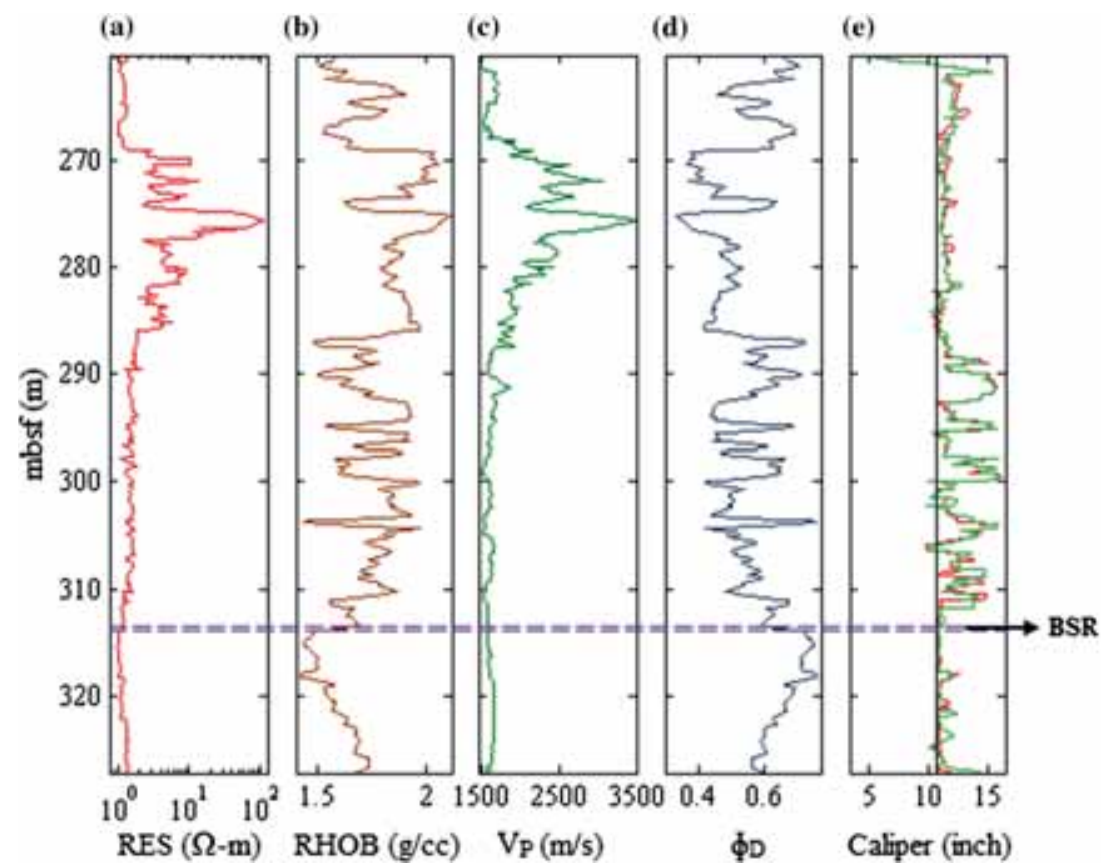

Figure 3. Wireline log responses of (a) resistivity $\log (\mathrm{RES}),(\mathbf{b})$ bulk density $\log (\mathrm{RHOB})$, (c) P-wave velocity log ( $\left.V_{\mathrm{P}}\right)$, (d) density porosity $\log \left(\phi_{\mathrm{D}}\right)$, and $(\mathbf{e})$ calliper log at hole NGHP-02-17-C.

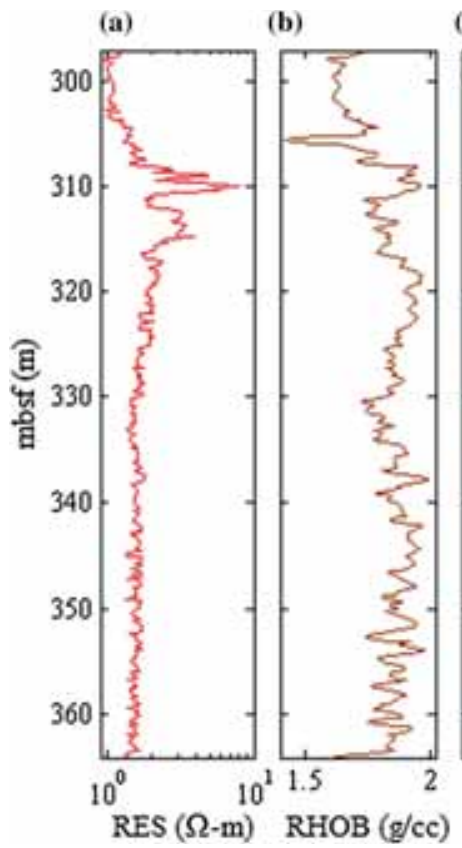

(c)

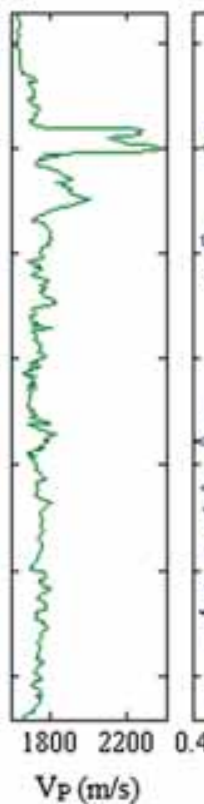

(d)

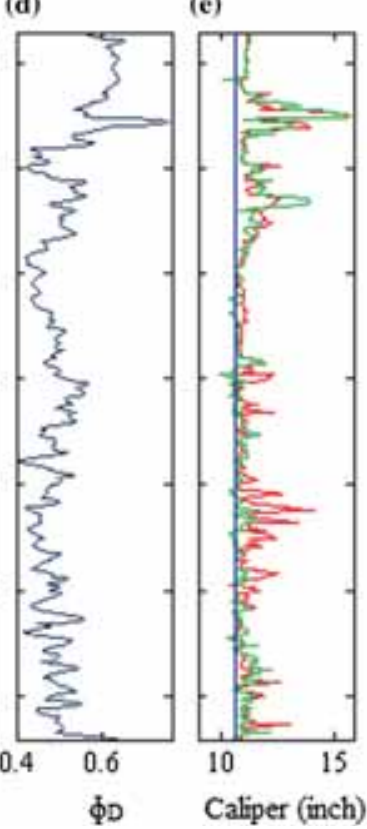

Figure 4. Wireline log responses of (a) resistivity log (RES), (b) bulk density log (RHOB), (c) P-wave velocity log ( $\left.V_{\mathrm{P}}\right)$, (d) density porosity $\log \left(\phi_{\mathrm{D}}\right)$, and (e) calliper log at hole NGHP-02-19-C.

factor $(F)$ and pore water resistivity $\left(R_{\mathrm{w}}\right)$ has been established by Archie (1942) as

$$
F=\frac{R_{\mathrm{o}}}{R_{\mathrm{w}}}
$$

The formation factor is also expressed as

$$
F=\frac{a}{\phi^{m}}
$$

where $a$ is Archie's exponent, varies with lithology, $\phi$ denotes the porosity and $m$ denotes the cementation factor. The $R_{\mathrm{w}}$ is obtained using Arp's (1953) formula with a seafloor temperature 

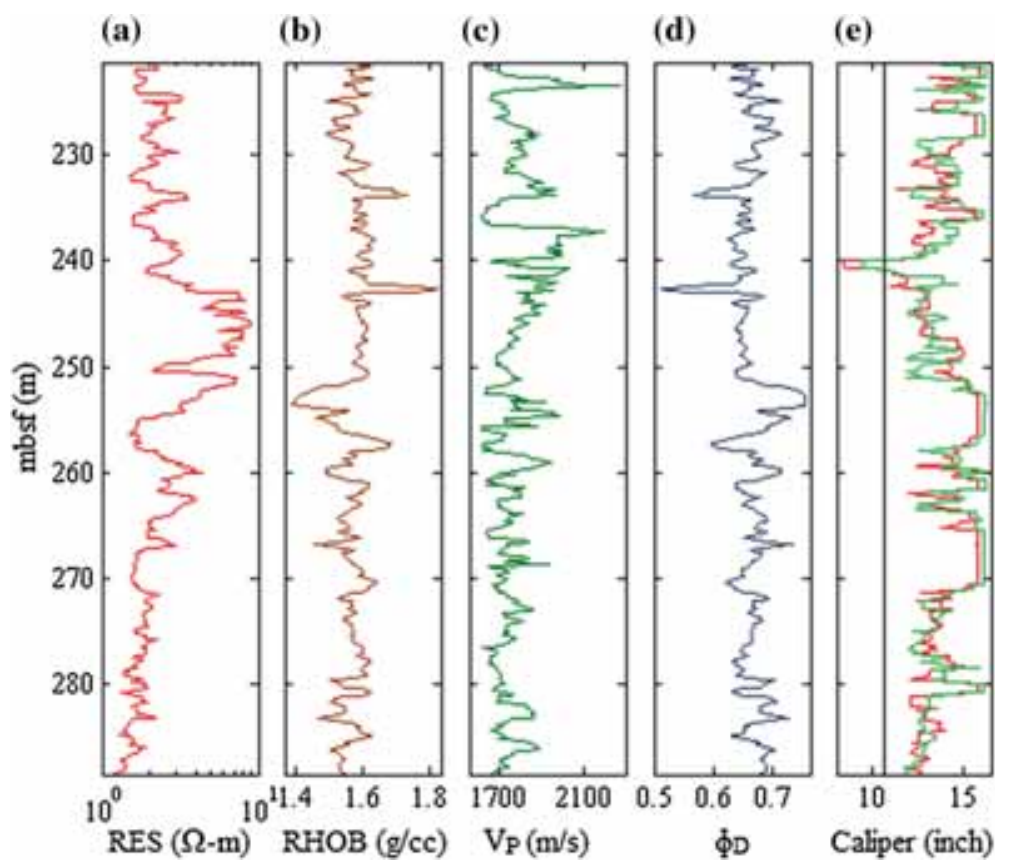

Figure 5. Wireline log responses of (a) resistivity log (RES), (b) bulk density log (RHOB), (c) P-wave velocity log ( $\left.V_{\mathrm{P}}\right)$, (d) density porosity $\log \left(\phi_{\mathrm{D}}\right)$, and $(\mathbf{e})$ calliper log at hole NGHP-02-22-C.

of $6.5^{\circ} \mathrm{C}$ (Collett et al. $\left.2008 \mathrm{~b}\right)$ and temperature gradient of 70,58 and $64^{\circ} \mathrm{C} / \mathrm{km}$ for the holes NGHP-02-17-C, NGHP-02-19-C and NGHP-0222-C, respectively (Kumar et al. 2016b). Arp's formula is given by

$$
R_{\mathrm{w} 2}=R_{\mathrm{w} 1}\left(\frac{T_{1}+21.5}{T_{2}+21.5}\right)
$$

where $R_{\mathrm{w} 1}$ and $R_{\mathrm{w} 2}$ are water resistivities at temperatures $T_{1}$ and $T_{2}$, matched by laboratory measurements and subsurface formation conditions, respectively.

The saturation $\left(S_{\mathrm{h}}\right)$ of gas hydrates is calculated as

$$
S_{\mathrm{h}}=1-\left(\frac{R_{\mathrm{o}}}{R_{\mathrm{t}}}\right)^{1 / n},
$$

where $R_{\mathrm{t}}$ is the resistivity of the formation, Archie's saturation exponent $(n)$ is generally adjusted in the laboratory by measuring the resistivity of a core sample. The value of $n$ is related to the saturation, wettability, porosity and clay content (Sweeney and Jennings 1960; Waxman and Smits 1968; Swanson 1985). The appropriate calibration of $n$ is still a subjective task in gas hydrate reservoirs. We need to choose all the constants ( $a, m$ and $n$ ) in such a way that the calibrated values of constants mimic the in-situ environment of the deposition pattern of gas hydrates. For the gas hydrate study, previous researchers have suggested that $n$ could vary from 0.5 to 4 (Spangenberg 2001). Kennedy and Herrick (2004) showed that $n$ can vary from 1.25 to 7 . The respective values of $a, m$ and $n$ are derived at 1.2 , 2.1 and 2 for the hole NGHP-02-17-C; $1.21,2.22$ and 2.05 for the hole NGHP-02-19-C and 1.3, 2.71 and 1.4 for the hole NGHP-02-22-C. We calculate the porosity from the bulk density wireline log data.

The target for the prediction of gas hydrate saturation using the ANN is from the log data. As we have very limited core data at the drilling sites, we have derived the saturation of gas hydrates by modified Archie's equation (with adjusting Archie's parameters) in such a way that the logderived saturations corroborate with the available core data.

Initially, the resistivity, bulk density and $\mathrm{P}$-wave velocity log data at hole NGHP-02-17-C are taken as the input and porosity as the output for designing the porosity network (network-1) with a view to predict the porosity at the holes NGHP-0219-C and NGHP-02-22-C, respectively. Similarly, the resistivity, bulk density, $\mathrm{P}$-wave velocity and density porosity data at hole NGHP-02-17-C were used as inputs and traditionally estimated saturation of gas hydrates (corroborated with the 
Table 1. Statistical analysis of the wireline log data (442 data points).

\begin{tabular}{|c|c|c|c|c|c|c|c|}
\hline Well ID & $\begin{array}{c}\text { Log } \\
\text { name }\end{array}$ & Minimum & Maximum & Mean & $\begin{array}{l}\text { Standard } \\
\text { deviation }\end{array}$ & Kurtosis & Skewness \\
\hline \multirow[t]{4}{*}{ NGHP-02-17-C } & $R_{\mathrm{t}}$ & 0.9636 & 114.9174 & 4.1324 & 12.3934 & 6.611 & 46.097 \\
\hline & RHOB & 1.4216 & 2.1132 & 1.7427 & 0.1612 & -0.882 & 0.044 \\
\hline & $V_{\mathrm{P}}$ & 1441.156 & 3479.441 & 1788.5494 & 369.7958 & 4.968 & 2.209 \\
\hline & $\phi_{\mathrm{D}}$ & 0.3313 & 0.7583 & 0.5498 & 0.0977 & -0.882 & -0.044 \\
\hline \multirow[t]{4}{*}{ NGHP-02-19-C } & $R_{\mathrm{t}}$ & 0.9678 & 8.0092 & 1.7582 & 0.6979 & 23.159 & 4.003 \\
\hline & RHOB & 1.4231 & 1.9958 & 1.8309 & 0.0972 & 1.172 & -1.108 \\
\hline & $V_{\mathrm{P}}$ & 1622.92 & 2373.657 & 1761.3022 & 108.3947 & 12.767 & 3.226 \\
\hline & $\phi_{\mathrm{D}}$ & 0.4038 & 0.7573 & 0.5055 & 0.0600 & 1.172 & 1.108 \\
\hline \multirow[t]{4}{*}{ NGHP-02-22-C } & $R_{\mathrm{t}}$ & 1.232 & 9.3697 & 2.7284 & 1.6699 & 3.805 & 2.096 \\
\hline & RHOB & 1.4234 & 1.8191 & 1.5720 & 0.0503 & 3.166 & 0.131 \\
\hline & $V_{\mathrm{P}}$ & 1644.1987 & 2135.5393 & 1757.6840 & 75.2379 & 2.018 & 1.18 \\
\hline & $\phi_{\mathrm{D}}$ & 0.5129 & 0.7571 & 0.6534 & 0.0311 & 3.49 & 0.054 \\
\hline
\end{tabular}

pressure core data) as outputs for designing the saturation network (network-2) with a view to predict the saturation of gas hydrates at the holes NGHP-02-19-C and NGHP-02-22-C, respectively. For both the networks (network-1 and network-2), about $70 \%$ of input data (wireline log data and corresponding porosity/saturations of gas hydrates at NGHP-02-17-C) are taken for network training, $15 \%$ data for network testing and the remaining $15 \%$ data are used for validation. The statistical analysis is given in table 1 .

Since the wells under study are located nearby, the geological conditions are almost the same. The best validation performances of the networks (network-1 and network-2) are found at epochs 652 and 908 (figure 6). Basically, an epoch in BP learning is a measure of the number of times, all of the training vectors are used to update the weights. Each epoch builds a particular model from the existing network with a set of weights. Subsequently, we find a model that provides the best generalisation performance.

As a diagnostic step for the ANN analysis, the validation and test errors are checked to understand the training progress. It is seen from figure 6(a and b) that the test curve had not increased significantly before the validation curve increased. The test error curves and validation error curves have similar trends for both the networks. Thus, the networks are ready to analyse the log data at neighbour holes. The training, validation and testing are shown in figures 7 and 8 for network-1 and network-2, respectively, corresponding to a linear regression fit $\left(R^{2} \approx 0.9\right)$ between the inputs (log data) and the output (porosity and saturation). Usually, the higher the $R^{2}$ value is, the smaller the difference between the target and prediction. The log data
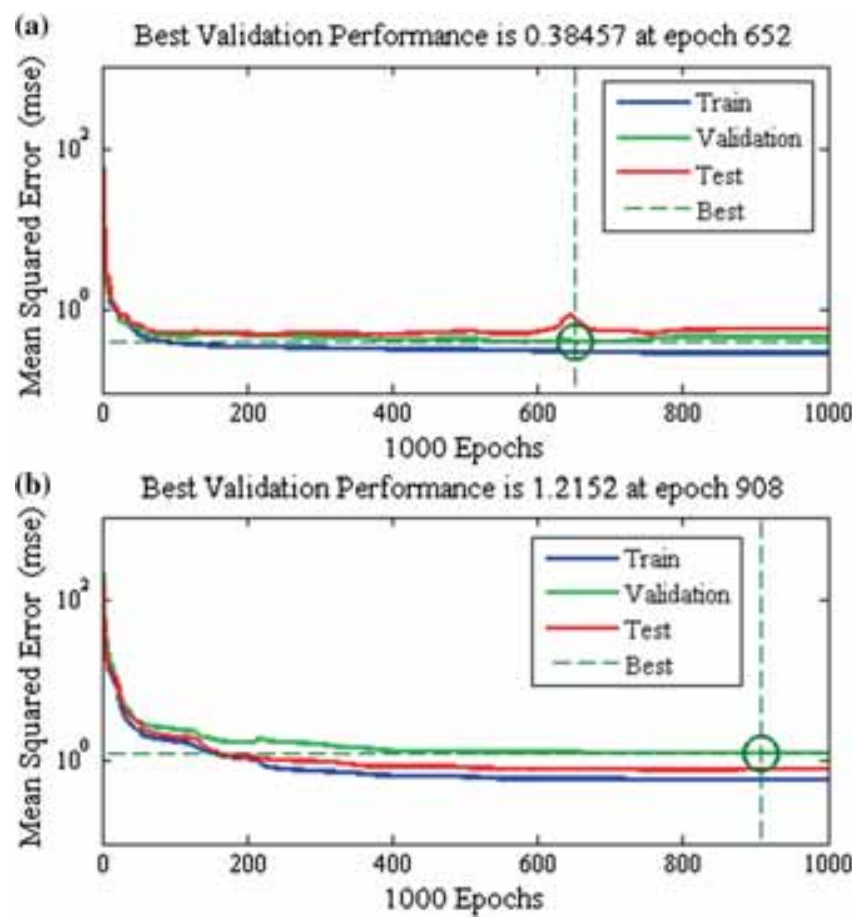

Figure 6. Network performance for (a) porosity prediction (network-1) and (b) saturation prediction for gas hydrates (network-2).

from holes NGHP-02-19-C and NGHP-02-22-C are simulated through the defined networks (network-1 and network-2) to generate the final predicted porosity and saturation of gas hydrates for holes NGHP-02-19-C and NGHP-02-22-C, respectively. The ANN-predicted porosity and traditionally estimated porosity for all the holes under study are shown in figure 9. Similarly, the ANN-predicted saturation and traditionally estimated saturation of gas hydrates for all the holes are shown in figure 10. The correlation coefficients between the 

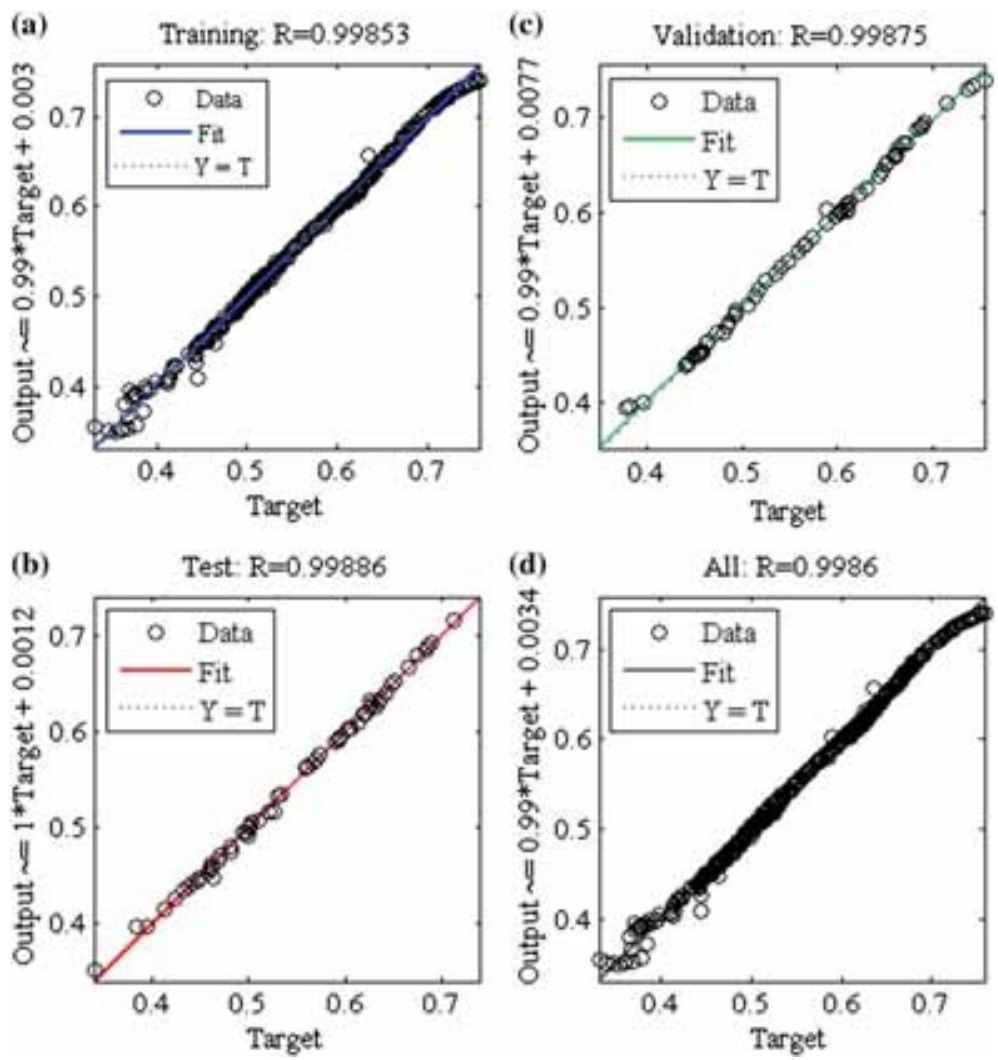

Figure 7. (a) Training, (b) test, (c) validation, and (d) overall results for porosity prediction (network-1) at site NGHP-02-17-C.
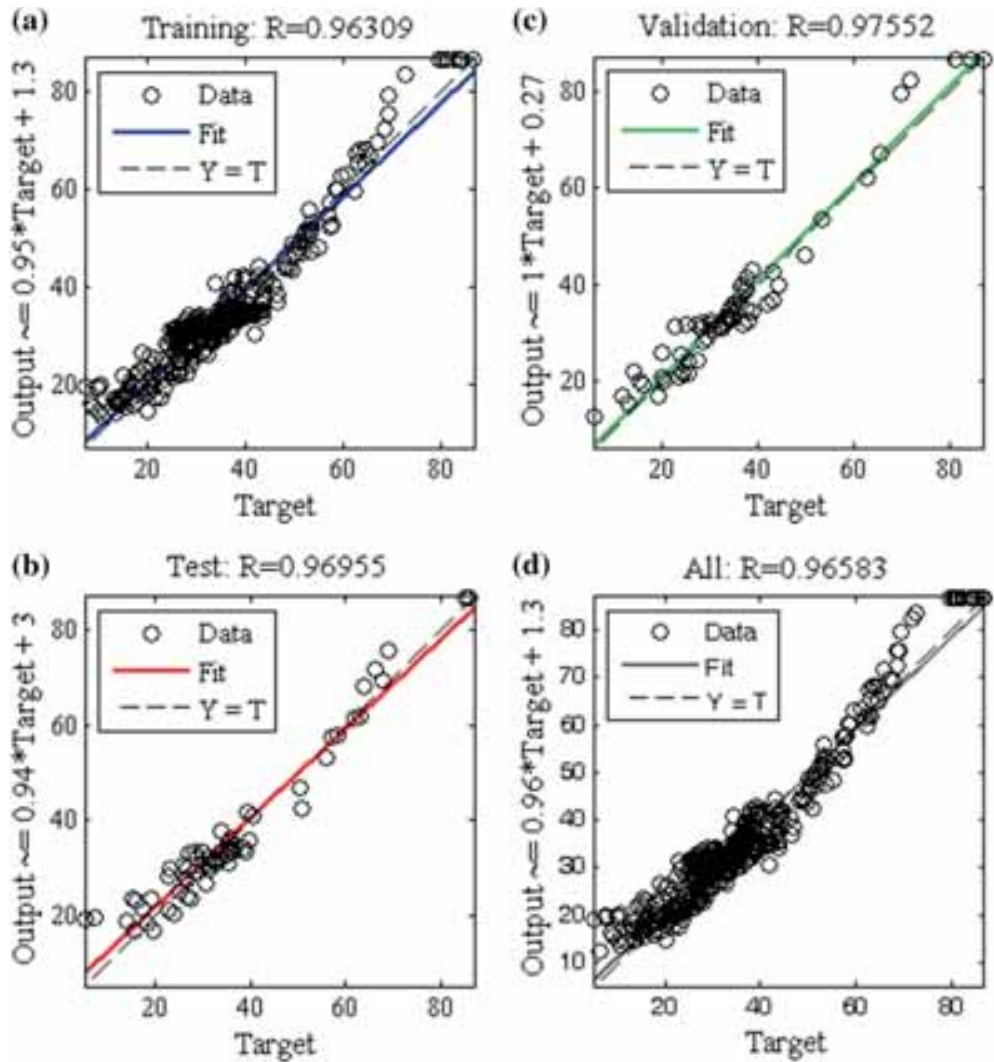

Figure 8. (a) Training, (b) test, (c) validation, and (d) overall results for the saturation prediction of gas hydrates (network-2) at site NGHP-02-17-C. 
(a)

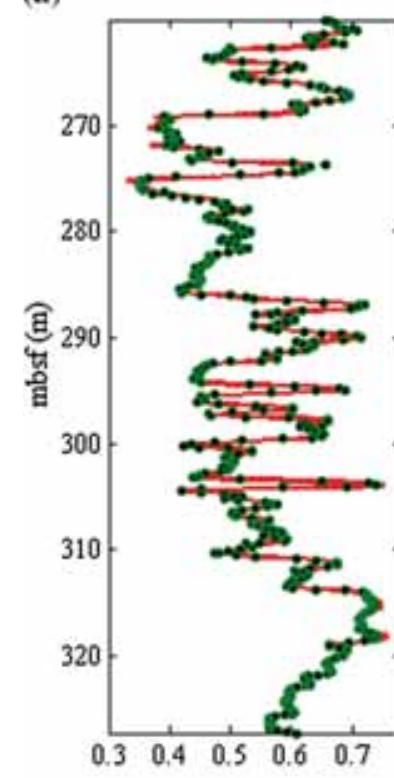

(b)

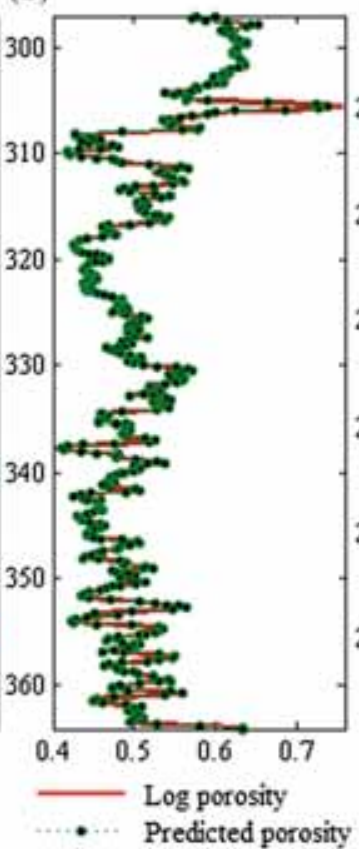

(c)

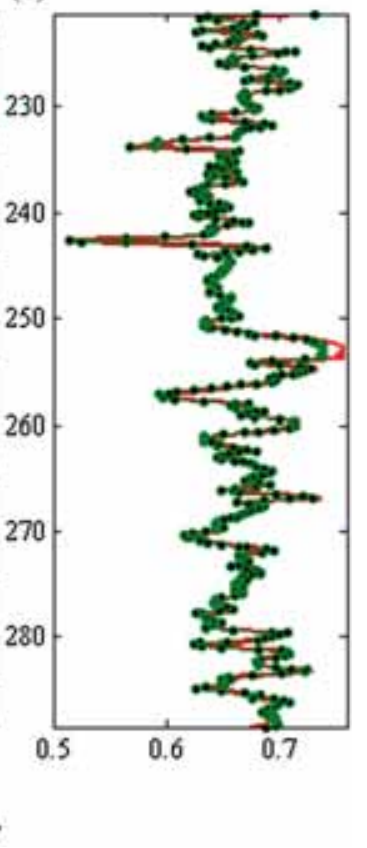

Figure 9. Comparison between the traditionally estimated porosity and ANN predicted porosity at (a) NGHP-02-17-C, (b) NGHP-02-19-C, and (c) NGHP-02-22-C sites.

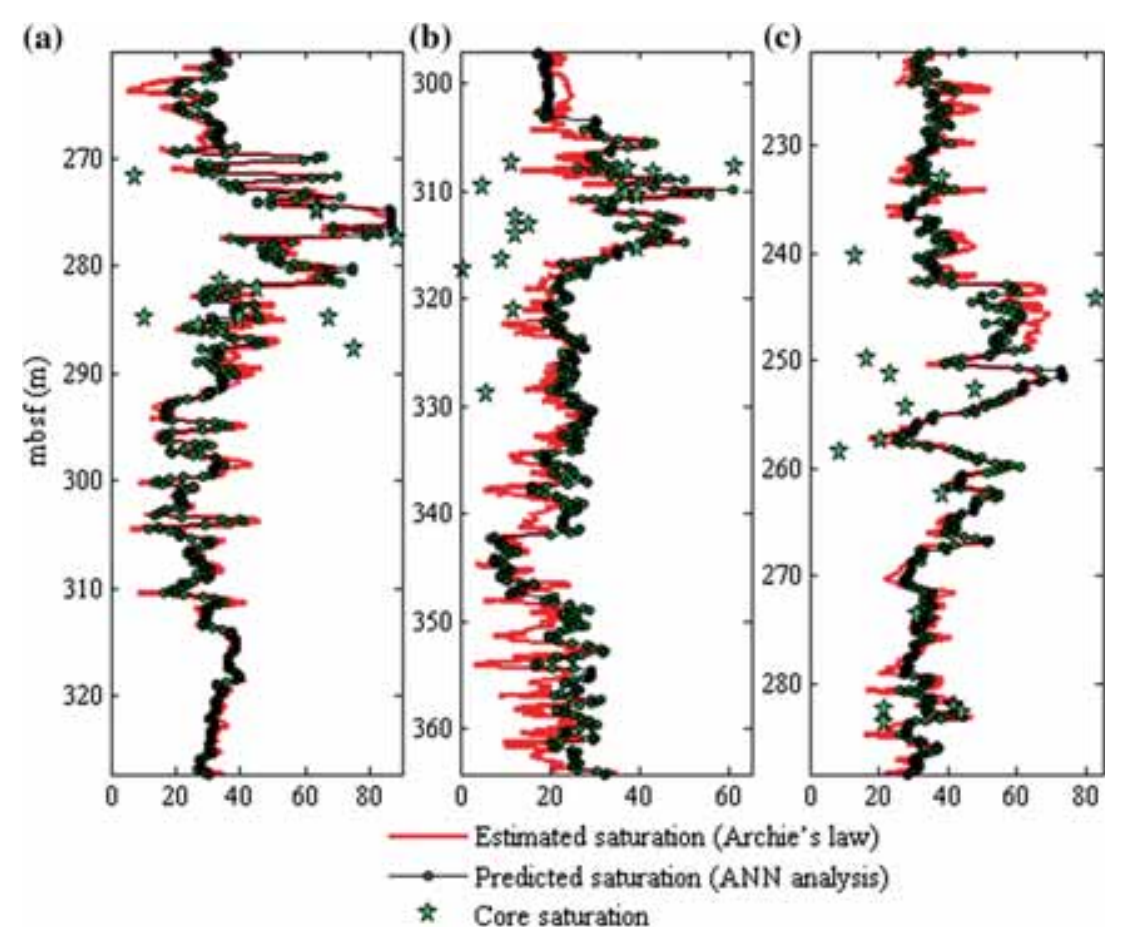

Figure 10. Comparison between the traditionally estimated saturation and ANN predicted saturation of gas hydrates at (a) NGHP-02-17-C, (b) NGHP-02-19-C, and (c) NGHP-02-22-C sites.

traditionally estimated porosity and the saturation of gas hydrates with the predicted porosity and saturation using the ANN analysis are given in table 2 . The strong correlation of more than 0.7 in both the cases shows that the predicted results are reasonable.

\section{Discussion}

We have used the MLF neural network to predict the petrophysical parameters such as the porosity and saturation of gas hydrates. We derive the saturation of gas hydrates from the wireline log 
Table 2. Correlation coefficients between the traditional estimation and ANN prediction.

\begin{tabular}{lcc}
\hline & $\begin{array}{c}\text { Correlation coefficient } \\
\text { between traditional and } \\
\text { ANN predicted porosity }\end{array}$ & $\begin{array}{c}\text { Correlation coefficient between } \\
\text { traditional and ANN predicted } \\
\text { saturation of gas hydrates }\end{array}$ \\
\hline NGHP-02-17-C & 0.99 & 0.96 \\
NGHP-02-19-C & 0.99 & 0.89 \\
NGHP-02-22-C & 0.99 & 0.95 \\
\hline
\end{tabular}

data at holes (NGHP-02-17-C, 19-C and 22-C) in the KG basin by employing modified Archie's law, which varies between $3.39 \%$ and $86.92 \%$. The MLF network predicts the saturation of gas hydrates varying between $6.55 \%$ and $86.92 \%$, and matches reasonably with the core-derived saturation varying between $0.5 \%$ and $88.53 \%$. The overall log-derived porosity varies from 0.33 to 0.76 , whereas the MLF network predicts the porosity from 0.35 to 0.74 . We find a strong correlation between the log derived and MLF network predicted reservoir parameters (porosity and saturation of gas hydrates). The saturation results are validated by core data. The saturation of gas hydrates from NGHP Exp-02 data in the KG basin is found to be higher than the values, estimated by the earlier researchers using the log data of NGHP Exp-01 in the KG basin. Kumar et al. (2009) documented gas hydrate saturation varying from $5 \%$ to $40 \%$ of pore spaces; Jana et al. (2017) estimated average gas hydrate saturation of $\sim 10 \%$ of the pore volume from log data at sites $10 \mathrm{~A}$ and $13 \mathrm{~A}$ of NGHP Exp-01 and Pandey et al. (2013) reported gas hydrates varying from $5 \%$ to $28 \%$ both laterally and vertically based on the analysis of wireline log at sites $10 \mathrm{~A}$ and $10 \mathrm{D}$ (NGHP Exp-01) along with the seismic data.

The designing of a network is one of the important aspects in a machine learning study. Several researchers have proposed thumb-rules on how to find out the optimal number of hidden nodes. Blum (1992) has proposed that the number of hidden nodes should be somewhere between the size of the input and output layers. Boger and Guterman (1997) documented that the dimension of the hidden node need to capture 70-90\% of the variance of the input data. Sarle (2002) has endorsed that the optimum number of hidden nodes depends on the size of input and output units, number of training cases, noises in the targets, complexity of the transfer function and training algorithm. However, the proposed thumb-rules are not applicable to most cases. The complexity of the data set must be taken into account (Xu and Chen 2008). Fletcher et al. (1998) suggested that the optimum nodes should be selected on the basis of minimising the MSE. Helle et al. (2001) documented that there are no rigorous rules to choose the number of hidden layers and the number of nodes in the hidden layers. In a multi-layer network, the weights associated with nodes in each hidden layer are adjusted and passed through the additional layers before reaching the output. The error is fed backwards through the network and the weights are adjusted in such a way to achieve the minimum misfit between the targets and the prediction. We have used the trial and error method for the selection of hidden nodes based on the minimisation of MSE.

The porosity can be traditionally calculated from the sonic or bulk density or neutron-porosity or resistivity log data based on an empirical relationship, which depend on the density of formation fluid, shale content, compactness, etc. Instead of searching for a complicated interrelationship among the geophysical properties, the machine learning approach can predict the porosity without any underlying mathematical model. Sometimes, we may not have the required log data and/or incomplete $\log$ data at a drilling site. Once the network is trained, the porosity can be predicted at other drilling sites based on available log data. That is why we have used the ANN approach for the prediction of porosity.

The wells under this study are located close to each other and there is no evidence of major fault(s) or other geological features between the wells. Therefore, the variation of petrophysical properties acquired from the wells in terms of wireline log data is almost similar. Thus, the geological resemblance of the study area is an incidental fact to get good correlation between AI predicted and log-derived parameters (porosity and saturation). Other than the geological cause, the proper sample training, network training, optimum number of hidden layers and hidden nodes also play an important role in obtaining good 
correlation between the AI-predicted and logderived parameters (porosity and saturation).

Statistically, the sonic velocity and porosity do not hold linear relationship (Saputro et al. 2016). Based on laboratory analysis of field data, Vedanti et al. (2018) suggested that the velocity and density show a nonlinear relationship when the porosity exceeds $10 \%$. Hence, we have used the nonlinear transfer function in a machine learning technique. Earlier researchers (Verma et al. 2012; Singh et al. 2016) have also used the nonlinear transfer function for the porosity prediction. Helle et al. (2001) and Bhatt (2002) showed that improper number of neurons in the hidden layer may introduce nonlinearity between the input and output. The optimal configuration can only be accomplished by testing and learning through experiences with the data quality and the problems being studied. The correlation coefficient of 0.89-0.99 between the traditionally log-derived petrophysical parameters and the ANN prediction shows the reliability of machine learning application to geophysical data. It is to be mentioned that the effect of different drilling fluids (like oil-based mud or water-based mud) has not been taken into account. It may be required to recognise the behaviour of the network with respect to different drilling fluids in future work.

\section{Conclusions}

We have applied the MLF network to wireline log data (NGHP Exp-02) in the KG basin, and predicted the porosity and saturation of gas hydrates. The results match reasonably with the traditionally calculated values. Therefore, the designed network can be used to assess the petrophysical parameters at any other wells in the same reservoir. The predicted porosity from the resistivity, bulk density and P-wave velocity log data varies from $33 \%$ to $76 \%$. Whereas the saturation of gas hydrates, predicted from the resistivity, bulk density, P-wave velocity and density porosity log data, ranges from $3.39 \%$ to $86.92 \%$. From the analysis of wireline log data by ANN, we draw following conclusions.

The AI has the ability to predict the porosity and saturation of gas hydrates from wireline log data without rigorous calculations that are involved in appropriate calibrations of Archie's constant, particularly for non-conventional resources like gas hydrates, etc.

Since the network model results depend on specific site sample data, these models should not be used in other regions without additional site specific calibration (i.e., network training).

The computational efficiency of the ANN suggests that it can be further exploited for analysing large data sets with a greater degree of accuracy.

Since the MLF network does not require a priori knowledge of the rock matrix and pore fluids, we can evaluate the petrophysical parameters in the absence of the said information.

\section{Acknowledgements}

We are thankful to the Director, CSIR-National Geophysical Research Institute, Hyderabad for permission to publish this work (Ref. No.: NGRI/Lib/ 2019/Pub-32). We are grateful to the Ministry of Petroleum and Natural Gas (Government of India), Oil and Natural Gas Corporation Limited (ONGC), Directorate General of Hydrocarbons (DGH), Oil India Limited (OIL), Gas Authority of India Limited (GAIL), Indian Oil Corporation Limited (IOCL) and all other NGHP partner organizations for providing the opportunity to contribute to the NGHP Exp-02. The technical and science support from Japan Agency for Marine-Earth Science and Technology (JAMSTEC), United States Geological Survey (USGS), U.S. Department of Energy (US-DOE), the National Institute of Advanced Industrial Science and Technology (AIST), Geotek Coring and Schlumberger is gratefully acknowledged. The author also acknowledges the anonymous reviewers for improving the manuscript. The first author acknowledges the Science and Engineering Research Board (SERB) (Project No. SERB/PDF/2017/ 001331), Government of India, for the financial support. The Ministry of Earth Sciences is acknowledged for extending support in pursuing research on gas hydrates at CSIR-NGRI. This is contributed to the In-house project MLP-6402-28(KS).

\section{References}

Aminian K and Ameri S 2005 Application of artificial neural networks for reservoir characterization with limited data; $J$. Petrol. Sci. Eng. 49(3) 212-222, https://doi.org/10.1016/j. petrol.2005.05.007.

Archie G E 1942 The electrical resistivity log as an aid in determining some reservoir characteristics; J. Petrol. Technol. 1 55-62.

Arps J J 1953 The effect of temperature on the density and electrical resistivity of sodium chloride solutions; J. Petrol. Technol. 175 17-20. 
Benaouda D, Wadge G, Whitmarsh R B, Rothwell R G and MacLeod C 1999 Inferring the lithology of borehole rocks by applying neural network classifiers to downhole logs: An example from the ocean drilling program; Geophys. J. Int. 136(2) 477-491.

Bhatt A 2002 Reservoir properties from well logs using neural networks; PhD Thesis, Department of Petroleum Engineering and Applied Geophysics, Norwegian University of Science and Technology.

Blum A 1992 Neural networks in $C++$ : An object-oriented framework for building connectionist systems; Wiley, New York.

Boger Z and Guterman H 1997 Knowledge extraction from artificial neural network models; In: IEEE systems, man, and cybernetics conference, Orlando, FL, USA.

Boswell R, Collett T S, Frye M, Shedd W, McConnell D R and Shelander D 2012 Subsurface gas hydrates in the northern Gulf of Mexico; Mar. Petrol. Geol. 34(1) 4-30, https://doi. org/10.1016/j.marpetgeo.2011.10.003.

Chatterjee R, Singha D K, Ojha M, Sen M K and Sain K 2016 Porosity estimation from pre-stack seismic data in gashydrate bearing sediments Krishna-Godavari basin, India; J. Nat. Gas Sci. Eng. 33 562-572, https://doi.org/10.1016/ j.jngse.2016.05.066.

Collett T S 2000 Quantitative well-log analysis of in-situ natural gas hydrates; PhD Thesis, Colo. Sch. of Mines, Golden, 535p.

Collett T S 2002 Energy resource potential of natural gas hydrates. AAPG Bull. 86 1971-1992.

Collett T S et al. 2008a National Gas Hydrate Program Expedition 01 initial report; Directorate General of Hydrocarbons, Ministry of Petroleum and Natural Gas, New Delhi.

Collett T S, Riedel M, Cochran J R, Boswell R, Kumar P and Sathe A V 2008b Indian continental margin gas hydrate prospects: Results of the Indian National Gas Hydrate Program (NGHP Exp-01; In: Proceedings of the 6th international conference on gas hydrates (ICGH 2008), Vancouver, British Columbia, Canada.

Collett T S, Boswell R, Cochran J R, Kumar P, Lall M and Mazumdar A et al. 2014 Geologic implications of gas hydrates in the offshore of India: Results of the National Gas Hydrate Program Expedition 01; Mar. Petrol. Geol. 58(Part A) 3-28, https://doi.org/10.1016/j.marpetgeo. 2014.07.021.

Dickens G R, Paull C K and Wallace P 1997 Direct measurement of in-situ methane quantities in a large gashydrate reservoir; Nature 385 426-428.

Fausett L V 1993 Fundamentals of neural networks: Architectures, algorithms and applications (1st edn); Pearson Publication, India.

Fletcher L, Katkovnik V, Steffens F E and Engelbrecht A P 1998 Optimizing the number of hidden nodes of a feedforward artificial neural network; Proc. IEEE IJCNN 2 1608-1612.

Fung C C, Wong W K and Eren H 1997 Modular artificial neural network for prediction of petrophysical properties from well log data; IEEE Trans. Instrum. Meas. 46(6) 1295-1299.

Ghosh R, Sain K and Ojha M 2010 Effective medium modeling of gas hydrate-filled fractures using sonic log in the Krishna-Godavari basin, eastern Indian offshore; J. Geophys. Res. 115(B06101) 1-15.
Guerin G, Goldberg D and Melster A 1999 Characterization of in situ elastic properties of gas hydrate-bearing sediments on the Blake Ridge; J. Geophys. Res. 104(B8) 17,781-17,796, https://doi.org/10.1029/1999JB900127.

He M Y 1992 Neural computing; Xidian University Press, Xi'an, pp. 156-178.

Helgerud M B, Dvorkin J, Nur A, Sakai A and Collett T 1999 Elastic-wave velocity in marine sediments with gas hydrates: Effective medium modelling; Geophys. Res. Lett. 26 2021-2024, https://doi.org/10.1029/1999GL900421.

Helle H B, Bhatt A and Ursin B 2001 Porosity and permeability prediction from wireline logs using artificial neural networks: A North Sea case study; Geophys. Prospect. 49 431-444.

Holland M and Schultheiss P 2014 Comparison of methane mass balance and X-ray computed tomographic methods for calculation of gas hydrate content of pressure cores; Mar. Petrol. Geol. XXX 1-10, http://dx.doi.org/10.1016/ j.marpetgeo.2014.07.016.

Hyndman R D, Spence G D, Chapman R, Riedel M and Edwards R N 2001 Geophysical studies of marine gas hydrate in northern Cascadia; In: Natural gas hydrate: Occurrence, distribution, and detection (eds) Paul C K and Dillon W P, Geophys. Monogr. Ser. 124 273-295, AGU, Washington, DC.

Jana S, Ojha M, Sain K and Srivastava S 2017 An approach to estimate gas hydrate saturation from 3-D heterogeneous resistivity model: A study from Krishna-Godavari basin, Eastern Indian offshore; Mar. Petrol. Geol. 79 99-107.

Jiao L C 1992 The theory of artificial neural networks; Xidian University Press, Xi'an, pp. 35-51.

Kennedy W D and Herrick D C 2004 Conductivity anisotropy in shale-free sandstone; Petrophysics 45 38-58.

Kexiong W and Laibin Z 2008 Predicting formation lithology from $\log$ data by using a neural network; Petrol. Sci. 5 242-246, https://doi.org/10.1007/s12182-008-0038-9.

Kumar D, Dash R and Dewangan P 2009 Methods of gas hydrate concentration estimation with field examples; Geohorizons 653 76-86.

Kumar P, Collett T S, Vishwanath K, Shukla K M, Nagalingam J and Lall M V et al. 2016a Gas hydratebearing sand reservoir systems in the offshore of India: Results of the India National Gas Hydrate Program Expedition 02; Fire Ice 16 1-8.

Kumar P, Yamada Y, Furutani A, Vishwanath K and Collett T and NGHP-02 Operation \& Science Party 2016b India National Gas Hydrate Program R \& D Expedition 02 Comprehensive Post Expedition Report.

Lee M W and Collett T S 2005 Assessments of gas hydrate concentrations estimated from sonic logs in the Mallik 5L38 well, N. W. T., Canada; In: Scientific results for Mallik 2002 gas hydrate production research well program, Mackenzie Delta, Northwest Territories, Canada (eds) Dallimore S R and Collett T S, Bull. Geol. Surv. Can. 560 10p.

Lee M W and Waite W F 2008 Estimating pore-space gas hydrate saturations from well-log acoustic data; Geochem. Geophys. Geosyst. 9 Q07008, https://doi.org/10.1029/ 2008GC002081.

Lee M W and Collett T S 2009 Gas hydrate saturations estimated from fractured reservoir at site NGHP-01-10, KrishnaGodavari basin, India; J. Geophys. Res. 114(B07102) 1-13, https://doi.org/10.1029/2008JB006237. 
Linnainmaa S 1970 The representation of the cumulative rounding error of an algorithm as a Taylor expansion of the local rounding errors; Master's Thesis, Univ. Helsinki, pp. 6-7 (in Finnish).

Malinverno A, Kastner M, Torres M E and Wortmann U G 2008 Gas hydrate occurrence from pore water chlorinity and downhole $\operatorname{logs}$ in a transect across the northern Cascadia margin (Integrated Ocean Drilling Program Expedition 311; J. Geophys. Res. 113 B08103, https:// doi.org/10.1029/2008JB005702.

McCulloch W S and Pitts W 1943 A logical calculus of the ideas imminent in nervous activity; Bull. Math. Biophys. 5 $115-133$.

Moazzeni A and Haffar M A 2015 Artificial intelligence for lithology identification through real-time drilling data; $J$. Earth Sci. Clim. Change 6(3) 265, https://doi.org/10.4172/ 2157-7617.1000265.

Mohaghegh S 2000 Virtual-intelligence applications in petroleum engineering: Part 1 - Artificial neural networks (SPE-58046); J. Petrol. Technol. 52(9) 64-73.

Mohaghegh S, Areti R, Ameri S, Aminiand K and Nutter R 1996 Petroleum reservoir characterisation with the aid of artificial neural networks; J. Petrol. Sci. Eng. 16 263-274.

Nakutnyy P, Asghari K and Torn A 2008 Analysis of water flooding through application of neural networks; In: Canadian international petroleum conference, Calgary, Alberta, June $17-19$.

Nikravesh M and Aminzadeh F 2003 Soft computing for intelligent reservoir characterization and modelling; In: Book soft computing and intelligent data analysis in oil exploration (eds) Nikravesh M, Aminzadeh F and Zadeh L A, Elsevier Science, UK, pp. 3-32.

Pandey V, Sain K and Sen M K 2013 Estimation of gashydrates from seismic velocity-resistivity transformed data in the Krishna-Godavari basin, eastern Indian margin; In: 10th biennial international conference \& exposition, 248p.

Rogers S J, Fang J H, Karr C L and Stanley D A 1992 Determination of lithology from well logs using a neural network; AAPG Bull. 76(5) 731-739.

Rolon L F, Mohaghegh S D, Ameri S and Gaskari R 2005 Developing synthetic well logs for the upper Devonian units in southern Pennsylvania; SPE-98013, SPE Eastern Regional Meeting, 14-16 September, Morgantown, West Virginia, https://doi.org/10.2118/98013-MS.

Rumelhart D E, Hinton G E and Williams R J 1986 Learning representations by errors; Nature $\mathbf{3 2 9}$ (9) 533-536.

Ryu B, Collett T S, Riedel M, Kim G Y, Chun J and Bahk J et al. 2013 Scientific results of the second gas hydrate drilling expedition in the Ulleung basin (UBGH2); Mar. Petrol. Geol. 47 1-20, https://doi.org/10.1016/j.marpetgeo.2013.07.007.

Sain K 2017 A possible future energy resource; J. Geol. Soc. India 89 359-362.

Salehi M M, Rahmati M, Karimnezhad M and Omidvar P 2017 Estimation of the non-records logs from existing logs using artificial neural networks; Egypt J. Petrol. 26 957-968.

Saputro D O, Maulana Z L and Latief F D E 2016 Porosity log prediction using artificial neural network; J. Phys. Conf. Ser. 739 012092, https://doi.org/10.1088/1742-6596/739/ $1 / 012092$.

Sarle W S 2002 Neural network FAQ; ftp://ftp.sas.com/pub/ neural/FAQ.html.
Schlumberger 1989 Log interpretation principles/applications; Schlumberger Educational Services, Houston.

Serra O 1984 Fundamentals of well-log interpretation-1. Acquisition of logging data; Elsevier, Amsterdam.

Shankar U, Gupta D K, Bhowmick D and Sain K 2013 Gas hydrate and free gas saturations using rock physics modelling at site NGHP-01-05 and 07 in the Krishna-Godavari basin, eastern Indian margin; J. Petrol. Sci. Eng. 106 $62-70$.

Shankar U and Riedel M 2011 Gas hydrate saturation in the Krishna-Godavari basin from P-wave velocity and electrical resistivity logs; Mar. Petrol. Geol. 28(10) 1768-1778.

Singh S, Kanli A I and Sevgen S 2015 A general approach for porosity estimation using artificial neural network method: A case study from Kansas gas field; Stud. Geophys. Geod. 60(1) 130-140, https://doi.org/10.1007/s11200-015-0820-2.

Singh Y, Nair R R, Singh H, Datta P, Jaiswal P, Dewangan P and Ramaprasad T 2016 Prediction of gas hydrate saturation throughout the seismic section in Krishna-Godavari basin using multivariate linear regression and multi-layer feed forward neural network approach; Arab. J. Geosci. 9 415, https://doi.org/10.1007/s12517-016-2434-6.

Singha D K and Chatterjee R 2017 Rock physics modeling in sand reservoir through well log analysis, Krishna-Godavari basin, India; Geomech. Eng. 13(1) 99-117.

Singha D K, Chatterjee R and Sain K 2014 Application of multilayer feed forward neural network: Porosity mapping in gas hydrate sediment of Krishna-Godavari Basin, India; In: 76th EAGE conference \& exhibition, Amsterdam RAI, Netherlands.

Spangenberg E 2001 Modeling the influence of gas hydrate content on the electrical properties of porous sediments; J. Geophys. Res. 104(B4) 6535-6548.

Swanson B F 1985 Microporosity in reservoir rocks - It's measurement and influence on electrical resistivity; In: SPWLA 26th annual logging symposium.

Sweeney S and Jennings H 1960 Effect of wettability on the electrical resistivity of carbonate rock from a petroleum reservoir; J. Phys. Chem. 64(5) 551-553, https://doi.org/ $10.1021 / \mathrm{j} 100834 \mathrm{a} 009$.

Takahashi H, Fercho E and Dallimore S R 2005 Drilling and operations overview of the Mallik 2002 production research well program; In: Scientific results from the Mallik 2002 gas hydrate production research well program (eds) Dallimore $\mathrm{S}$ $\mathrm{R}$ and Collett T S, Mackenzie Delta, Northwest Territories, Canada; Bulletin No. 585, Geological Survey of Canada, Canada.

Ussler W III, Paull C K 2001 Ion exclusion associated with marine gas hydrate deposits; In: Natural gas hydrates: Occurrence, distribution, and detection (eds) Paull C K and Dillon W P, Geophys. Monogr. Ser. 124 41-51, AGU, Washington, DC.

Vedanti N, Malkoti A, Pandey O P and Shrivastava J P 2018 Ultrasonic P- and S-wave attenuation and petrophysical properties of Deccan Flood Basalts, India, as revealed by Borehole Studies; Pure Appl. Geophys. 175 2905-2930.

Verma A K, Cheadlea B A, Routrayc A, Mohanty W K and Mansinhaa L 2012 Porosity and permeability estimation using neural network approach from well log data; Geo. Conv. 1-6.

Wang B, Wang X and Chen Z 2013 A hybrid framework for reservoir characterization using fuzzy ranking and an artificial neural network; Comput. Geosci. 57 1-10. 
Waxman M H and Smits L J M 1968 Electrical conductivities in oil-bearing shaly sands; Soc. Petrol. Eng. J. 8(02) 107-122, https://doi.org/10.2118/1863-A.

Wiener J M, Rogers J R and Moll R F 1991 Predicting carbonate permeabilities from wireline logs using a back-propagation neural network; In: 61st Annual SEG international meeting, Abstract.

Xiao K, Zou C, Lu Z and Deng J 2017 Gas hydrate saturations estimated from pore-and fracture-filling gas hydrate reservoirs in the Qilian Mountain permafrost, China; Sci. RepUK 7(16258) 1-16, https://doi.org/10.1038/s41598-01716531-x.

Corresponding editor: Arkoprovo Biswas
Xu S and Chen L 2008 A novel approach for determining the optimal number of hidden layer neurons for FNN's and its application in data mining; In: 5th international conference on information technology and applications (ICITA), pp. 683-686.

Yamamoto K, Terao Y, Fujii T, Ikawa T, Seki M, Matsuzawa $\mathrm{M}$ and Kanno T 2014 Operational overview of the first offshore production test of methane hydrates in the Eastern Nankai Trough; In: Off shore technology conference (OTC25243-MS), https://doi.org/10.4043/25243-MS.

Zhuang Z Q, Wang X F and Wang D S et al. 1992 Neural networks and neural computers; Science Press, Beijing. 